\title{
The Causal Relationship between Coal consumption and Economic Growth in the BRICS countries: Evidence from Panel-Granger Causality Tests
}

\author{
Tsangyao Chang \\ Department of Finance, Feng Chia University, Taichung, Taiwan \\ Derick Deale, Rangan Gupta, Roulof Hefer, Roula Inglesi-Lotz*, Beatrice Simo-Kengne, \\ Department of Economics, University of Pretoria, South Africa \\ *Corresponding author: Email Roula.inglesi-lotz@ up.ac.za. Main campus, University of Pretoria, Hatfield, \\ Pretoria, South Africa. Tel: +27 124204504
}

\begin{abstract}
This paper empirically analyses the causal linkages between coal consumption and economic growth in the BRICS countries (Brazil, Russia, India, China and South Africa) using annual data from 1985 to 2009. Due to the common directions and principals of the BRICS countries with regards to energy, the employed panel causality methodology is chosen to account for both cross-section dependence and heterogeneity across countries. Empirical results provide evidence of no causal relationship between the two variables; suggesting that neither coal consumption nor economic growth is sensitive to each other. While this finding vindicates the neutrality hypothesis overall for the BRICS countries, the individual country results provide support for a unidirectional causality running from coal consumption to economic growth for China; the opposite for South Africa and bidirectional for India. Policies to reduce coal consumption will have a detrimental effect to India's economy. However, in the rest of the countries, policy makers should aim at step further from fossil-fuel generation - and specifically coal - of energy without the potential risks of having an impact to the economic growth and development.
\end{abstract}

Keywords: Coal consumption; Cross-sectional Dependency; Economic Growth; Heterogeneity; Panel Causality Test 


\section{Introduction}

Climate change is attributed to many to the high volumes of emissions steming from the fossil-fuel power generation. Coal is the main fossil-fuel type that has more environmental effect than any other fossil fuel source (US EPA, n.d.). Although the environmental positive effects of coal consumption reduction are undisputable, the discussions on whether choosing to reduce coal consumption for power generation is an economically viable option are continuous. Mostly developing countries have still large amounts of coal reserves but at the same time their economic growth is highly dependent on energy consumption but also vulnerable to international shocks. But also, the coal dependence of the economies globally is obvious (Wolde-Rufael, 2010).

The relationship between coal consumption and economic growth has received an increasing attention during the last decades with however, contradictory results regarding the direction of the causality between the two variables. The empirical evidence can be grouped into four categories corresponding to the four hypotheses derived from the energy-growth nexus literature, namely, conservation, growth, feedback and neutrality.

The conservation hypothesis supports the unidirectional causality running from economic growth to coal consumption or in other words, the higher the growth of the economy the higher the needs of energy and usually they are covered by coal burning. In this case policies aiming at reducing coal consumption will have little to no negative impact on economic growth. Yang (2000) provides support to the conservation hypothesis for Taiwan, suggesting that reducing coal consumption may not have an adverse effect on the economic growth. Wolde-Rufael (2010) also confirms the same hypothesis for China.

Conversely, the growth hypothesis suggests that there is unidirectional causality running from coal consumption to economic growth. In this case, policies with primary target the restraint of coal consumption will affect the economic growth negatively so policy makers should 
implement them with caution and usually in combination with severe macroeconomic policies. Wolde-Rufael (2010) is favourable to the growth hypothesis in India and Japan.

Further, some studies including Lee and Chang (2005) for Taiwan, Wolde-Rufael (2010) for South Africa and the US, Yoo (2006) for Korea and Apergis and Payne (2010) for a panel of OECD find the relevance of the feedback hypothesis. According to this hypothesis, there is a bidirectional causality between coal consumption and economic growth. In this case, coal consumption stimulates economic growth and economic growth induces more coal demand.

Except for these three categories, there are studies that concluded no evidence of causality in any direction between coal consumption and economic growth; hence validating the neutrality hypothesis (Jinke et al (2008) for a panel of countries and Ziramba (2009) for South Africa).

This study investigates the causal relationship between coal consumption and economic growth for the five major emerging economies, the BRICS (Brazil, Russia, India, China and South Africa) with ultimate purpose to derive appropriate policy implications. There is no other study that looks at these five major emerging economies together. Appreciating thus the possible interconnections between them, our paper also makes use of the bootstrap panel causality approach by Emirmahmutoglu and Kose (2011) which accounts for both heterogeneity and cross section dependence across countries. As Pesaran (2006) suggested, ignoring these issues can lead to substantial bias and size distortions. Though the BRICS members are all developing economies in transition, they may have different prevailing economic conditions as well as coal endowment and may have different energy policies with possibly heterogeneous energy consumption behaviour. However, living in globalised economy, a shock in one country may spill over into other countries. 
The rest of the paper is structured as follows. The next section presents the methodology followed by the data whilst empirical findings are discussed in Section 4 and section 5 concludes.

\section{Methodology}

\subsection{Preliminary Analysis}

As discussed in the Introduction, before proceeding with the main causality tests, we deal with the serious issues of possible cross-sectional dependency and slope heterogeneity. As pointed out by Granger (2003), the causality from one variable to another variable by imposing the joint restriction for the panel is a strong null hypothesis. Furthermore, as Breitung (2005) contends, the homogeneity assumption for the parameters is not able to capture heterogeneity due to region specific characteristics. In the coal consumption and economic growth nexus - as in many economic relationships - while there may be a significant relationship in some countries, vice versa may also be true in some other countries.

\subsection{Testing cross-section dependence}

To test for cross-sectional dependency, the Lagrange multiplier (LM hereafter) test of Breusch and Pagan (1980) has been extensively used in empirical studies. The procedure to compute the LM test requires the estimation of the following panel data model:

$y_{i t}=\alpha_{i}+\beta_{i}^{\prime} x_{i t}+u_{i t}$ for $i=1,2, \ldots, N ; t=1,2, \ldots, T$

where $i$ is the cross section dimension, $t$ is the time dimension, $x_{i t}$ is $k \times 1$ vector of explanatory variables, $\alpha_{i}$ and $\beta_{i}$ are respectively the individual intercepts and slope coefficients that are allowed to vary across states. In the LM test, the null hypothesis of nocross section dependence- $H_{0}: \operatorname{Cov}\left(u_{i t}, u_{j t}\right)=0$ for all $t$ and $i \neq j$ - is tested against the 
alternative hypothesis of cross-section dependence $H_{1}: \operatorname{Cov}\left(u_{i t}, u_{j t}\right) \neq 0$, for at least one pair of $i \neq j$. In order to test the null hypothesis, Breusch and Pagan (1980) developed the LM test as:

$$
L M=T \sum_{i=1}^{N-1} \sum_{j=i+1}^{N} \hat{\rho}_{i j}^{2}
$$

where $\hat{\rho}_{i j}$ is the sample estimate of the pair-wise correlation of the residuals from Ordinary Least Squares (OLS) estimation of equation (1) for each $i$. Under the null hypothesis, the $L M$ statistic has asymptotic chi-square with $N(N-1) / 2$ degrees of freedom. It is important to note that the LM test is valid for $\mathrm{N}$ relatively small and $\mathrm{T}$ sufficiently large.

However, the $C D$ test is subject to decreasing power in certain situations that the population average pair-wise correlations are zero, although the underlying individual population pairwise correlations are non-zero (Pesaran et al., 2008). Furthermore, in stationary dynamic panel data models the CD test fails to reject the null hypothesis when the factor loadings have zero mean in the cross-sectional dimension. In order to deal with these problems, Pesaran et al. (2008) propose a bias-adjusted test which is a modified version of the LM test by using the exact mean and variance of the LM statistic. The bias-adjusted LM test is:

$$
L M_{a d j}=\sqrt{\left(\frac{2 T}{N(N-1)}\right)} \sum_{i=1}^{N-1} \sum_{j=i+1}^{N} \hat{\rho}_{i j} \frac{(T-k) \hat{\rho}_{i j}^{2}-\mu_{T i j}}{\sqrt{v_{T i j}^{2}}}
$$

where $\mu_{T i j}$ and $v_{T i j}^{2}$ are respectively the exact mean and variance of $(T-k) \hat{\rho}_{i j}^{2}$, that are provided in Pesaran et al. (2008). Under the null hypothesis with first $\mathrm{T} \rightarrow \infty$ and then $\mathrm{N} \rightarrow \infty$, $L M_{a d j}$ test is asymptotically distributed as standard normal.

\subsection{Testing slope homogeneity}

The second issue investigated here is to test whether or not the slope coefficients are homogenous. The causality from one variable to another variable by imposing the joint 
restriction for the whole panel is the strong null hypothesis (Granger, 2003). Moreover, the homogeneity assumption for the parameters is not able to capture heterogeneity due to region specific characteristics (Breitung, 2005).

The most familiar way to test the null hypothesis of slope homogeneity- $H_{0}: \beta_{i}=\beta$ for all $i$ against the hypothesis of heterogeneity- $H_{1}: \beta_{i} \neq \beta_{j}$ for a non-zero fraction of pair-wise slopes for $i \neq j$ - is to apply the standard $F$ test. The $F$ test is valid for cases where the cross section dimension $(\mathrm{N})$ is relatively small and the time dimension $(\mathrm{T})$ of panel is large; the explanatory variables are strictly exogenous; and the error variances are homoscedastic. By relaxing homoscedasticity assumption in the $F$ test, Swamy (1970) developed the slope homogeneity test on the dispersion of individual slope estimates from a suitable pooled estimator. However, both the $F$ and Swamy's test require panel data models where $N$ is small relative to $T$ [27]. Pesaran and Yamagata (2008) proposed a standardized version of Swamy's test (the so-called $\tilde{\Delta}$ test) for testing slope homogeneity in large panels. The $\tilde{\Delta}$ test is valid as $(N, T) \rightarrow \infty$ without any restrictions on the relative expansion rates of $\mathrm{N}$ and $\mathrm{T}$ when the error terms are normally distributed. In the $\widetilde{\Delta}$ test approach, the first step is to compute the following modified version of the Swamy's test as in Pesaran and Yamagata (2008):

$$
\tilde{S}=\sum_{i=1}^{N}\left(\widehat{\beta}_{i}-\tilde{\beta}_{W F E}\right)^{\prime} \frac{x_{i}^{\prime} M_{\tau} x_{i}}{\tilde{\sigma}_{i}^{2}}\left(\hat{\beta}_{i}-\tilde{\beta}_{W F E}\right)
$$

where $\widehat{\beta}_{i}$ is the pooled OLS estimator, $\tilde{\beta}_{\text {WFE }}$ is the weighted fixed effect pooled estimator, $M_{\tau}$ is an identity matrix, the $\tilde{\sigma}_{i}^{2}$ is the estimator of $\sigma_{i}^{2}$. Then the standardized dispersion statistic is developed as:

$$
\tilde{\Delta}=\sqrt{N}\left(\frac{N^{-1} \tilde{S}-k}{\sqrt{2 k}}\right)
$$


Under the null hypothesis with the condition of $(N, T) \rightarrow \infty$ so long as $\sqrt{N} / T \rightarrow \infty$ and the error terms are normally distributed, the $\tilde{\Delta}$ test has asymptotic standard normal distribution. The small sample properties of $\tilde{\Delta}$ test can be improved under the normally distributed errors by using the following bias adjusted version:

$\tilde{\Delta}_{a d j}=\sqrt{N}\left(\frac{N^{-1} \tilde{S}-E\left(\tilde{z}_{i t}\right)}{\sqrt{\operatorname{var}\left(\tilde{z}_{i t}\right)}}\right)$

where the mean $E\left(\tilde{z}_{i t}\right)=k$ and the variance $\operatorname{var}\left(\tilde{z}_{i t}\right)=2 k(T-k-1) / T+1$.

The presence of cross-sectional dependence and heterogeneity over the sample period implies that the panel causality test that imposes the homogeneity restriction and does not account for spillover effects across units may result in misleading inferences; hence providing the rationale of using the bootstrap panel causality approach.

\subsection{Panel Granger Causality analysis}

Emirmahmutoglu and Kose (2011) propose a causality test in heterogeneous mixed panels based on the meta analysis of Fisher (1932). They extended the Lag Augmented VAR (LAVAR) approach by Toda and Yamamoto (1995), which use the level VAR model with extra dmax lags to test Granger causality between variables in heterogeneous mixed panels. Consider a level VAR model with $k_{i}+d \max _{i}$ lags in heterogeneous mixed panels:

$$
\begin{gathered}
x_{i, t}=\mu_{i}^{x}+\sum_{j=1}^{k_{i}+d \max _{i}} A_{11, i j} x_{i, t-j}+\sum_{j=1}^{k_{i}+d \max _{i}} A_{12, i j} y_{i, t-j}+\mu_{i, t}^{x} \\
y_{i, t}=\mu_{i}^{y}+\sum_{j=1}^{k_{i}+d \max _{i}} A_{21, i j} x_{i, t-j}+\sum_{j=1}^{k_{i}+d \max _{i}} A_{22, i j} y_{i, t-j}+\mu_{i, t}^{y}
\end{gathered}
$$

where $\mathrm{i}(\mathrm{i}=1, \ldots \ldots \mathrm{N})$ denotes individual cross-sectional units and $\mathrm{t}(\mathrm{t}=1, \ldots \ldots \mathrm{T})$ denotes time periods, $\mu_{i}^{x}$ and $\mu_{i}^{y}$ are two vectors of fixed effects, ${ }_{i, t}^{x}, \mu_{i, t}^{y}$, are column vectors of error terms, ki is the lag structure which is assumed to be known and may differ across crosssectional units, and dmaxi is the maximal order of integration in the system for each $i$. 
Following the bootstrap procedure by Emirmahmutoglu and Kose (2011), testing causality from $\mathrm{x}$ to $\mathrm{y}$ is summarized as follows:

1)Determine the maximal order dmaxi of integration of variables in the system for each cross-section unit based on the Augumented Dickey Fuller (ADF) unit root test and selet the lag orders kis via information criteria (AIC or SB) by esteeming the regression (2) using the OLS method. 2)Re-estimate equation (2) using the dmaxi and ki under the non-causality hypothesis and attain the residuals for each individual.

$\hat{u}_{i, t}^{y}=y_{i, t}-\hat{u}_{i}^{y}+\sum_{j=1}^{k_{i}+d \max _{i}} \hat{A}_{21, i j} x_{i, t-j}+\sum_{j=1}^{k_{i}+d \max _{i}} \hat{A}_{22, i j} y_{i, t-j}$

3)Residuals are centred using Stine's (1987) suggestion, i.e.,

$\tilde{u}_{t}=\hat{u}_{t}-(T-k-l-2)^{-1} \sum_{t=k+l+2}^{T} \hat{u}_{t}$

Where $\hat{\mu}_{t}=\left(\hat{\mu}_{1 t}, \hat{\mu}_{2 t}, \ldots . ., \hat{\mu}_{N t}\right)^{\prime}, k=\max \left(k_{i}\right)$ and $l=\max \left(d \max _{i}\right)$. Next, we develop the $\left[\tilde{\mu}_{i . t}\right]_{N \times T}$ from these residuals. We select randomly a full column with replacement from the matrix at a time to preserve the cross covariance structure of the errors. We denote the bootstrap residuals as $\tilde{\mu}_{t}^{*}$ where $\left.(t=1, \ldots ., T) .4\right)$ A bootstrap sample of y is generated under the null hypothesis, i.e.

$y_{i, t}^{*}=\hat{\mu}_{i}^{y}+\sum_{j=1}^{k_{i}+d \max _{i}} \hat{A}_{21, i j} x_{i, t-j}+\sum_{j=1}^{k_{i}+d \max _{i}} \hat{A}_{22, i j} y_{i, t-j}^{*}+u_{i, t}^{*}$

where $\hat{\mu}_{i}^{y} \hat{A}_{12, i j}$ and $\hat{A}_{22, i j}$ are the estimations from step 3. 5)For each individual, Wald statistics are calculated to test for the non-causality null hypothesis by substituting $y_{i, t}^{*}$ for $y_{i, t}$ and estimating equation (2) without imposing any parameter restrictions. 6) Using individual p-values (pi) that correspond to the Wald statistic of the ith individual crosssection, the Fisher test statistic $\lambda$ is obtained as follows: 
$\lambda=-2 \sum_{i=1}^{N} \ln \left(p_{i}\right) \quad \mathrm{i}=1, \ldots \ldots, \mathrm{N}$

7)The bootstrap empirical distribution of the Fisher test statistics are generated by repeating steps 3 to 510,000 times and specifying the bootstrap critical values by selecting the appropriate percentiles of these sampling distributions.

Using simulation studies, Emirmahmutoglu and Kose (2011) demonstrate that the performance of LA-VAR approach under both the cross-section independency and the crosssection dependency seem be satisfactory for the entire values of $\mathrm{T}$ and $\mathrm{N}$.

\section{Data}

The annual data used cover the period $1985-2009$ for the five BRICS countries. The real GDP is in constant 2005 Dollars and is estimated by multiplying population data obtained from the Quantec (n.d) database and the real GDP per capita data drawn from the Economic Research Service International Macroeconomic Data Set. Growth is defined as an increase in this real GDP figure. The coal consumption data are obtained from the British Petroleum Statistical Review of World Energy (BP, 2012) and is measured in million on tons, oil equivalent and refers to commercial solid fuels only. All the data are in their logarithmic form and their descriptive statistics are presented in Table 1.

Table1. Summary Statistics of Coal Consumption (Million tonnes oil equivalent) Coal consumption (million tonnes of oil equivalent)

\begin{tabular}{|c|c|c|c|c|c|c|c|}
\hline Country & Mean & Maximum & Minimum & Std. Dev. & Skewness & Kurtosis & $\begin{array}{l}\text { Jarque- } \\
\text { Bera } \\
\end{array}$ \\
\hline BRAZIL & 11,44307 & 13,928 & 9,533 & 1,349936 & 0,342 & 1,907 & 1,870 \\
\hline RUSSIA & 128,916 & 205,114 & 90,23 & 41,13959 & 0,849 & 2,077 & 4,204 \\
\hline INDIA & 149,6312 & 295,6151 & 72,54392 & 59,7445 & 0,931 & 3,028 & 3,899 \\
\hline CHINA & 852,3035 & 1839,446 & 399,7984 & 423,0372 & 0,992 & 2,668 & 4,552 \\
\hline RSA & 75,39576 & 95,1345 & 61,18429 & 10,47562 & 0,369 & 1,913 & 1,943 \\
\hline GDP & \multicolumn{7}{|c|}{ (Billions of US \$) } \\
\hline Country & Mean & Maximum & Minimum & Std. Dev. & Skewness & Kurtosis & Jarque- \\
\hline
\end{tabular}




\begin{tabular}{|c|c|c|c|c|c|c|c|}
\hline & & & & & & \multicolumn{2}{|c|}{ Bera } \\
\hline BRAZIL & 755,67 & 1082,53 & 537,23 & 158,18 & 0,606 & 2,260 & 2,267 \\
\hline RUSSIA & 726,41 & 948,98 & 483,44 & 155,53 & $-0,194$ & 1,564 & 2,490 \\
\hline INDIA & 641,24 & 1393,16 & 267,41 & 327,21 & 0,845 & 2,627 & 3,371 \\
\hline CHINA & 1565,23 & 4223,30 & 359,51 & 1145,08 & 0,918 & 2,704 & 3,891 \\
\hline RSA & 206,78 & 306,29 & 151,26 & 50,53 & 0,660 & 2,037 & 3,004 \\
\hline
\end{tabular}

Figure 1 illustrates the average coal consumption and average GDP for the BRICS countries from 1985 to 2009. As can be seen, the two variables follow an upward trend that intensified from the beginning of 2000 s.

Figure 1: Average GDP (in billions) and average coal consumption (in Mtoe) for BRICS

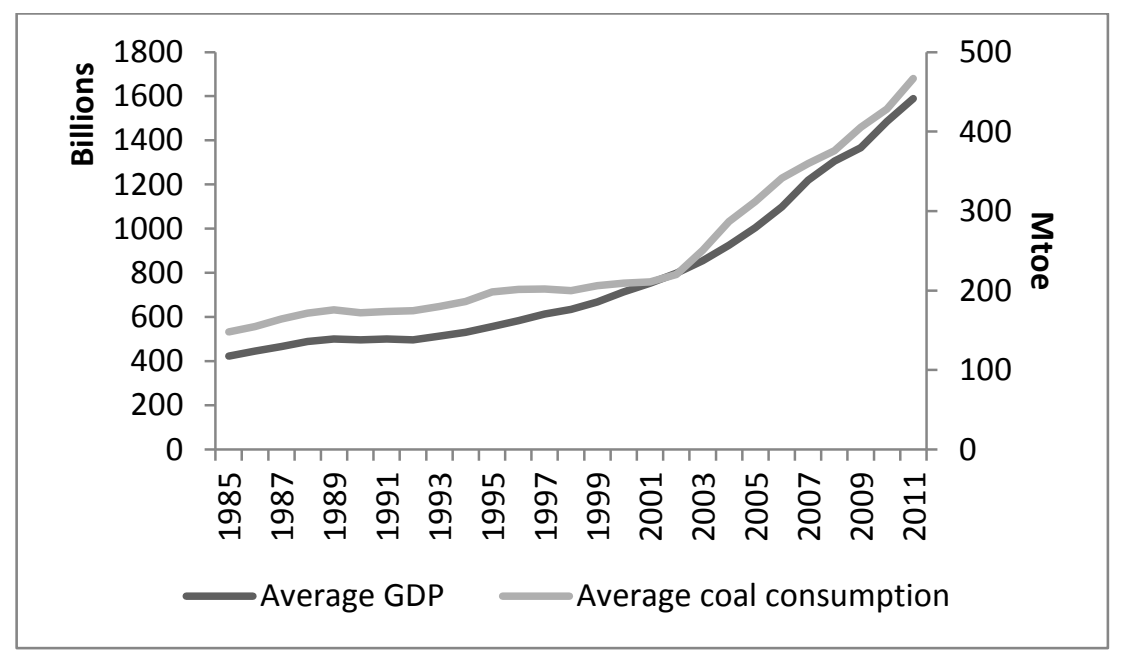

Source: Quantec (n.d.) and BP (2012)

\section{Empirical results}

To investigate the existence of cross section dependence, we performed four different tests, as described in the Methodology section: $\mathrm{LM}, \mathrm{CD}_{\mathrm{lm}}, \mathrm{CD}$ and $\mathrm{LM}_{\text {adj. }}$. The null hypothesis for all these tests is that there is no cross-sectional dependency. According to the results presented in Table 2, the null hypothesis is strongly rejected in favour of the alternative that supports the existence of cross-sectional at a $1 \%$ level of significance, which means that a shock in one country may spill over onto other countries. The last three rows present the results of testing for slope homogeneity. Although $\tilde{\Delta}_{a d j}$ fails to reject the null of slope 
homogeneity, both Swamy -Shat and $\tilde{\Delta}$ reject the null in favour of slope heterogeneity, meaning that country specific characteristics should be taken into account. The results of Table 2 confirm the validity of the bootstrap panel causality approach proposed by Emirmahmutoglu and Kose (2011) that takes into account these econometric issues.

Table 2. Cross-sectional Dependence and Homogeneous Tests

\begin{tabular}{lc}
\hline \hline $\mathbf{C D}_{\mathbf{B P}}$ & $23.519^{* * * *}$ \\
$\mathbf{C D}_{\mathbf{L M}}$ & $3.023^{* * *}$ \\
$\mathbf{C D}$ & $3.572^{* * *}$ \\
$\mathbf{L} \mathbf{M}_{\text {adi }}$ & $58.0833^{* * *}$ \\
& \\
$\tilde{\Delta}$ & $12.2236^{* * *}$ \\
$\tilde{\Delta}$ & 0.4953 \\
SWAMY SHAT & $40.3007 * * *$ \\
\hline
\end{tabular}

Note: $* * *, * *$, and $*$ indicate significance at the $0.01,0.05$, and 0.1 levels, respectively.

Table 3 presents the results of the causality test running from coal consumption to GDP. As can be seen, the panel statistics (in both choices of information criteria: Akaike or Schwartz) support the neutrality hypothesis (no causality from coal consumption to GDP) for all the countries examined. However, the individual statistics confirm the hypothesis of the causality from coal consumption to GDP for the case of India and China. Similarly, the panel causality test could not validate the growth-driven coal hypothesis with a Fisher statistic less than the bootstrap critical values at different levels of significance (See Table 5). However, the individual cross-sectional results (based on slope heterogeneity) show that for the case of South Africa the causality direction from economic growth to coal consumption is confirmed while for India, there is some evidence that the hypothesis holds, using the Schwartz Information criterion. 
Table 3

Causality running from Coal Consumption to GDP

Causality running from GDP to Coal Consumption

Results based on AIC Information criteria

\begin{tabular}{|c|c|c|c|c|c|c|c|c|}
\hline \multicolumn{5}{|c|}{ Individual Statistics } & \multicolumn{4}{|c|}{ Individual Statistics } \\
\hline Country & & Lag Length & Wald Stat & p-value & Country & Lag Length & Wald Stat & $\mathrm{p}$-value \\
\hline BRAZIL & & 2 & 0.262 & 0.87 & BRAZIL & 2 & 0.912 & 0.634 \\
\hline RUSSIA & & 2 & 0.218 & 0.897 & RUSSIA & 2 & 1.611 & 0.447 \\
\hline INDIA & & 2 & $6.756^{* *}$ & 0.034 & INDIA & 2 & 2.194 & 0.334 \\
\hline CHINA & & 3 & $7.228 *$ & 0.065 & CHINA & 3 & 0.341 & 0.952 \\
\hline SOUTH AFRICA & & 2 & 1.043 & 0.594 & SOUTH AFRICA & 2 & $6.635^{* *}$ & 0.036 \\
\hline \multicolumn{5}{|c|}{ Panel Statistics } & \multicolumn{4}{|c|}{ Panel Statistics } \\
\hline \multirow{3}{*}{ Fisher test value } & \multicolumn{4}{|c|}{ Bootstrap critical values } & \multicolumn{4}{|c|}{ Bootstrap critical values } \\
\hline & & $\mathrm{CV} 1 \%$ & CV $5 \%$ & CV $10 \%$ & Fisher test value & $\mathrm{CV} 1 \%$ & CV $5 \%$ & CV $10 \%$ \\
\hline & 13.746 & 31.523 & 23.614 & 19.978 & 11.45 & 32.44 & 23.678 & 19.921 \\
\hline \multicolumn{9}{|c|}{ Results based on AIC Information criteria } \\
\hline \multicolumn{5}{|c|}{ Individual Statistics } & \multicolumn{4}{|c|}{ Individual Statistics } \\
\hline Country & & Lag Length & Wald Stat & p-value & Country & Lag Length & Wald Stat & p-value \\
\hline BRAZIL & & 1 & 0.547 & 0.46 & BRAZIL & 1 & 0.08 & 0.778 \\
\hline RUSSIA & & 2 & 0.218 & 0.87 & RUSSIA & 2 & 1.611 & 0.447 \\
\hline INDIA & & 1 & $6.524 * *$ & 0.011 & INDIA & 1 & $3.794 *$ & 0.051 \\
\hline CHINA & & 2 & $0.330^{*}$ & 0.063 & CHINA & 2 & 0.159 & 0.924 \\
\hline SOUTH AFRICA & & 1 & 1.297 & 0.255 & SOUTH AFRICA & 1 & $4.658 * *$ & 0.031 \\
\hline \multicolumn{5}{|c|}{ Panel Statistics } & \multicolumn{4}{|c|}{ Panel Statistics } \\
\hline \multirow{3}{*}{ Fisher test value } & \multicolumn{4}{|c|}{ Bootstrap critical values } & & \multicolumn{3}{|c|}{ Bootstrap critical values } \\
\hline & & CV $1 \%$ & CV 5\% & CV $10 \%$ & Fisher test value & CV $1 \%$ & CV 5\% & CV $10 \%$ \\
\hline & 14.526 & 29.17 & 21.99 & 18.625 & 15.16 & 30.526 & 22.048 & 18.758 \\
\hline
\end{tabular}

Note: $* * *, * *$, and $*$ indicate significance at the $0.01,0.05$, and 0.1 levels, respectively, also highlighted with grey colour 


\section{Conclusion}

Coal is considered to be the most 'popular' fossil fuel consumed for power generation internationally. This study examined the causality between coal consumption and economic growth for the BRICS group of major emerging economies for the period from 1980 to 2009 . To do so, the bootstrap panel Granger causality approach proposed by Emirmahmutoglu and Kose (2011) was employed to take into account possible cross-sectional dependency and slope heterogeneity.

The overall panel results confirm the neutrality hypothesis, meaning that there is no causality running from coal consumption to economic growth or vice versa. These findings confirm those by Jinke et al. (2008) who also found no causality between these two variables.

However, the individual results support that there are exceptions. For China specifically, this result suggests causality runs from coal consumption to GDP meaning that coal consumption might be a vital input alongside capital and labour in the production process. Although, the Chinese policy makers make efforts to increase the contribution of renewables and more importantly nuclear power to the supply mix, such policies which seek to reduce the usage of coal as a source of energy could potentially be harmful to economic growth in the country. For India, consistent with Apergis and Payne (2010), the results suggest that there is bidirectional causality between the two variables. Hence, except for coal being an important input, higher economic growth leads to increases in the coal consumption to supply the necessary demand. Thus, policies which seek to reduce the usage of coal as a source of energy could potentially be harmful to economic growth in this country.

On the contrary for South Africa, whose results confirm Wolde-Rufael (2010), the higher economic growth of the economy in the last three decades have boosted the demand for energy that primarily is generated by coal due to the substantial coal reserves in the country. 
In this case, environmental policies to reduce coal generated electricity will not affect the economic growth of the country and certainly have a positive impact on the environment.

\section{References}

Abosedra, S., Baghestani, H. 1989. New evidence on the causal relationship between United States energy consumption and gross national product. Journal of Energy and Development 14:285-292.

Apergis, N. and Payne, J.E. 2010. The causal dynamics between coal consumption and growth: Evidence from emerging market economies. Applied Energy 87:1972-1977

BP. 2012. Petroleum Statistical review of world energy. Available at: http://www.bp.com/liveassets/bp_internet/globalbp/globalbp_uk_english/reports_and_publica tions/statistical_energy_review_2011/STAGING/local_assets/pdf/statistical_review_of_worl d_energy_full_report_2012.pdf

Breitung, J. 2005. A parametic approach to the estimation of co-integration vectors in panel data. Econometric Reviews 24:151-173.

Breusch, T. S. and Pagan, A. R. 1980. The Lagrange Multiplier test and its applications to model specification in econometrics. The Review of Economic Studies 47(1):239-253.

Emirmahmutoglu, F. and Kose, N. 2011. Testing for Granger causality in heterogeneous mixed panels. Economic Modelling 28:870-876.

Fisher, R.A., 1932. Statistical Methods for Research Workers, 4th edition. Oliver and Boyd, Edinburgh.

Granger, C.W.J. 2003. Some aspects of causal relationships. Journal of Econometrics 112:69-71.

Jinke L, Hualing S, Dianming G. 2008. Causality relationship between coal consumption and GDP: difference of major OECD and non-OECD countries. Applied Energy 85:421-429.

Lee CC, Chang CP. 2005. Structural breaks, energy consumption and economic growth revisited: evidence from Taiwan. Energy Economics 27:857-872.

Pesaran, M. H. 2006. Estimation and Inference in Large Heterogeneous Panels with Multifactor Error Structure. Econometrica 74(4):967-1012.

Pesaran, M. H. and Yamagata, T. 2008. Testing slope homogeneity in large panels. Journal of Econometrics 142:50-93.

Pesaran, M. H., Ullah, A. and Yamagata, T. 2008. A bias-adjusted LM test of error crosssection independence. Econometrics Journal 11:105-127.

Quantec (n.d.). Quantec Economic Databases. Available at: www.quantec.co.za

Swamy, P.A.V.B. 1970. Efficient inference in a random coefficient regression model. Econometrica 38:311-323.

Toda, H.Y., Yamamoto, T., 1995. Statistical inference in vector auto-regressions with possibly integrated processes. Journal of Econometrics 66:225-250.

US EPA (Environmental Protection Agency), n.d. Coal-Electriicity from coal. Available at: http://www.epa.gov/cleanenergy/energy-and-you/affect/coal.html . Last accessed: 27 February 2014. 
Wolde-Rufael, Y. 210. Coal consumption and economic growth revisited. Applied Energy, 87:160-167.

World Bank. 2007 and 2008. World development indicators 2007 and 2008.

Yang, H.Y., 2000. Coal consumption and economic growth in Taiwan. Energy Sources 22:109-115.

Yoo, S.H. 2006. Causal relationship between coal consumption and economic growth in Korea. Applied Energy 83(11):1187-1189.

Ziramba E. 2009. Disaggregate energy consumption and industrial production in South Africa. Energy Policy 37:2214-2220. 